\title{
Metabolic Activity of Radish Sprouts Derived Isothiocyanates in Drosophila melanogaster
}

\author{
Nieves Baenas ${ }^{1,2}$, Stefanie Piegholdt ${ }^{1}$, Anke Schloesser ${ }^{1}$, Diego A. Moreno ${ }^{2}$, \\ Cristina García-Viguera ${ }^{2}$, Gerald Rimbach ${ }^{1}$ and Anika E. Wagner ${ }^{1, *}$ \\ 1 Institute of Human Nutrition and Food Science, University of Kiel, Hermann-Rodewald-Strasse 6, \\ 24118 Kiel, Germany; nbaenas@cebas.csic.es (N.B.); piegholdt@foodsci.uni-kiel.de (S.P.); \\ schloesser@foodsci.uni-kiel.de (A.S.); rimbach@foodsci.uni-kiel.de (G.R.) \\ 2 Department of Food Science and Technology, CEBAS-CSIC, Campus de Espinardo 25, 30100 Murcia, Spain; \\ dmoreno@cebas.csic.es (D.A.M.); cgviguera@cebas.csic.es (C.G.-V.) \\ * Correspondence: wagner@molecularnutrition.uni-kiel.de; Tel.: +49-431-880-5313
}

Academic Editor: Manickam Sugumaran

Received: 13 January 2016; Accepted: 5 February 2016; Published: 18 February 2016

\begin{abstract}
We used Drosophila melanogaster as a model system to study the absorption, metabolism and potential health benefits of plant bioactives derived from radish sprouts (Raphanus sativus cv. Rambo), a Brassicaceae species rich in glucosinolates and other phytochemicals. Flies were subjected to a diet supplemented with lyophilized radish sprouts $(10.6 \mathrm{~g} / \mathrm{L})$ for 10 days, containing high amounts of glucoraphenin and glucoraphasatin, which can be hydrolyzed by myrosinase to the isothiocyanates sulforaphene and raphasatin, respectively. We demonstrate that Drosophila melanogaster takes up and metabolizes isothiocyanates from radish sprouts through the detection of the metabolite sulforaphane-cysteine in fly homogenates. Moreover, we report a decrease in the glucose content of flies, an upregulation of spargel expression, the Drosophila homolog of the mammalian $\operatorname{PPAR} \gamma$-coactivator $1 \alpha$, as well as the inhibition of $\alpha$-amylase and $\alpha$-glucosidase in vitro. Overall, we show that the consumption of radish sprouts affects energy metabolism in Drosophila melanogaster which is reflected by lower glucose levels and an increased expression of spargel, a central player in mitochondrial biogenesis. These processes are often affected in chronic diseases associated with aging, including type II diabetes mellitus.
\end{abstract}

Keywords: Brassicaceae; sulforaphene; radish; spargel; energy metabolism

\section{Introduction}

Obesity and related diseases, such as diabetes and cardiovascular diseases, are a growing and serious health problem in both industrialized and developing countries [1]. The consumption of cruciferous plants (Brassicaceae family) has been associated with beneficial metabolic effects, although the underlying cellular and molecular mechanisms have not yet been fully elucidated [2-4]. Brassicaceae contain high amounts of glucosinolates (GLS), bioactive compounds that are enzymatically hydrolyzed to several breakdown products, including isothiocyanates (ITC, Figure 1). Treatment with indole-3-carbinol (I3C) and 3,3'-diindolylmethane (DIM), hydrolysis products of the GLS glucobrassicin, has been shown to significantly decrease blood glucose levels in C57BL/6 mice receiving a high fat diet [5]. Furthermore, patients suffering from type II diabetes exhibited significantly improved fasting glucose and lower insulin levels as well as an augmented homeostasis model assessment of insulin resistance (HOMA-IR) index following the consumption of $10 \mathrm{~g} /$ day broccoli sprout powder for four weeks [6]. Radish sprouts have been widely studied because of their high content of potentially health-promoting GLS $[7,8]$. The main compounds glucoraphenin and glucoraphasatin, belonging to the aliphatic group 
of GLS, are hydrolyzed by the plant endogenous enzyme myrosinase (thioglucoside glucohydrolase, EC 3.2.1.147), following plant tissue disruption to sulforaphene (SFE; 4-methylsulfinyl-3-butenyl ITC) and raphasatin (RPS; 4-methylsulfanyl-3-butenyl ITC), respectively [9]. Also, indole GLS, such as glucobrassicin, 4-hydroxyglucobrassicin and 4-methoxyglucobrassicin, are present in radish sprouts and have been studied because of their breakdown product I3C, which has been associated with improved glucose tolerance and modulated expression of adipokines and lipogenic-associated gene products, including acetyl-CoA carboxylase and peroxisome proliferator-activated receptor- $\gamma$ [10].

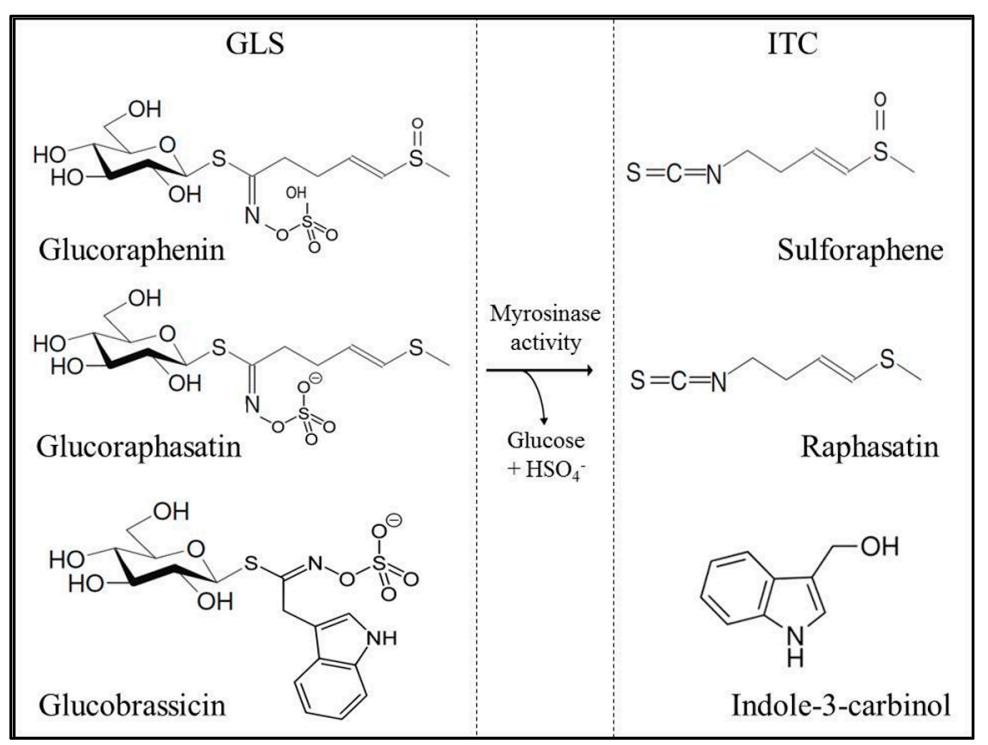

Figure 1. Glucosinolates in radish sprouts and their corresponding hydrolysis to isothiocyanates.

In mammals ITC are known to be metabolized in the enterocytes and the liver through the mercapturic acid pathway. Initially, a reaction between the $-\mathrm{N}=\mathrm{C}=\mathrm{S}$ group of the ITC and the cysteine sulfhydryl group of glutathione (GSH) catalyzed by glutathione-S-transferase (GST) takes place. Next, hepatic enzyme modifications of the GSH moiety to cysteinylglycine (-cys-gly), cysteine (cys), and $\mathrm{N}$-acetyl-cysteine (NAC) conjugates are formed in the kidney of mammalian species [11]. Little is known about the absorption, metabolism and metabolic effects of ITC in model organisms. In this study, the fruit fly Drosophila melanogaster is used as a model system for studying the absorption and metabolism of ITC in lyophilized radish sprouts. In addition, the bioactivity of these compounds in terms of glucose and energy metabolism is evaluated.

\section{Results and Discussion}

\subsection{Glucosinolate and Isothiocyanate Content in Radish Sprouts}

The GLS profile of Brassicaceae species varies by genotype [12]. Radish sprouts (Raphanus sativus cv. Rambo) display a characteristic GLS profile, which has been extensively studied because of its hydrolysis products, ITC and indoles. ITC and indoles have been suggested to have protective effects on disease development through anti-inflammatory, chemopreventive and epigenetic pathways [13]. The concentrations of GLS are the highest in seeds and decline exponentially with sprout development. Aliphatic GLS are the predominant compounds in eight-day-old radish sprouts. Glucoraphenin and glucoraphasatin account for approximately $40 \%$ and $50 \%$ of the total GLS, respectively, as summarized in Table 1.

Following endogenous myrosinase hydrolysis of glucoraphenin and glucoraphasatin, these compounds released SFE and RPS, respectively. RPS is the oxidized counerpart of SFE and was not detected with our UHPLC method because a commercial standard was not available. However, this 
compound has been reported to be highly unstable, with a half-life of less than 30 min [9]. Besides its instability RPS has been reported to significantly induce the expression of detoxifying enzmyes [14]. In addition to SFE, we also detected sulforaphane (SFN) in the hydrolyzed samples. The detection of SFN is interesting because glucoraphanin, the precursor of SFN, was not detected in our radish sprouts. However, these molecules only differ chemically by one double bond, suggesting that SFN exists as a natural product or that the presence of SFN is an artifact of the analytical technique, as we did not find any reports of this conversion taking place. We also detected indole GLS, which accounts for $15 \%$ of the total GLS in our radish sprouts. In particular, 4-hydroxyglucobrassicin and 4-methoxyglucobrassicin were present at higher amounts than glucobrassicin and neoglucobrassicin (Table 1). Their main hydrolysis compound, I3C (1 mg/100 g F.W. (Fresh Weight)), has been shown to lead to decreases in body weight via its effect on fat accumulation and blood glucose levels in mice $[5,10]$.

Table 1. Quantification of glucosinolates and isothiocyanates in radish sprouts.

\begin{tabular}{cc}
\hline Glucosinolate Content in Radish Sprouts (mg/100 g F.W.) \\
\hline Glucoraphenin & $202 \pm 18.3$ \\
4-Hydroxyglucobrassicin & $19.9 \pm 1.32$ \\
Glucoerucin & $8.74 \pm 1.85$ \\
Glucoraphasatin & $250 \pm 23.5$ \\
Glucobrassicin & $6.48 \pm 0.36$ \\
4-Methioxyglucobrassicin & $19.5 \pm 0.72$ \\
Neoglucobrassicin & $6.51 \pm 0.31$ \\
Aliphatic GLS & $461 \pm 42.3$ \\
Indole GLS & $52.4 \pm 1.97$ \\
Total & $514 \pm 44.0$ \\
\hline Isothiocyanate Content in Radish Sprouts (mg/100 g F.W.) \\
\hline Sulforaphene & $9.93 \pm 0.01$ \\
Sulforaphane & $0.97 \pm 0.02$ \\
Indole-3-carbinol & $1.00 \pm 0.09$ \\
Total & $11.9 \pm 0.11$ \\
\hline Mean values $(n=3) \pm$ SD. F.W. (Fresh Weight).
\end{tabular}

\subsection{Evaluation of Food Intake and Fitness in Drosophila melanogaster}

Food intake did not differ between control flies and radish sprout-treated flies (Figure 2a). Climbing ability, as a marker of overall fitness of the flies, did not show statistically significant differences between groups (Figure $2 b$ ), indicating that supplementation of the SY medium with lyophilized radish sprouts did not affect the movement of the flies.

a

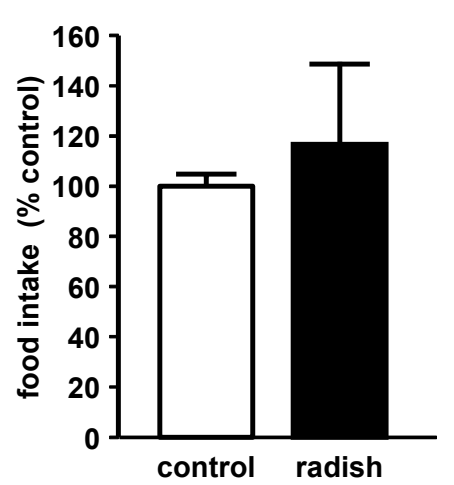

$\mathrm{b}$

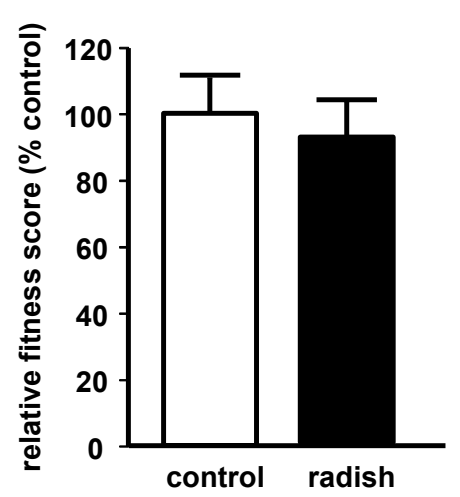

Figure 2. Effect of 10-day radish sprout supplementation on male Drosophila melanogaster. (a) relative food intake analyzed by the gustatory assay ( $n=3+$ SEM; extraction from $3 \times 15$ flies); (b) relative fitness score detected by the RING assay $(n=3+$ SEM). 
The isothiocyanates SFE, SFN and I3C were present in our flies in concentrations of nanomol per gram on a fresh weight basis. Thus, under the conditions investigated, the natural conversion of glucosinolates to isothiocyanates, by the plant-derived enzyme myrosinase but also by gut microflora-derived myrosinase, may have occurred [3].

Flies principally accumulate the ITC SFE (1.11 nmol/g F.W. in flies, Figure 3). SFN was also found to be present in radish sprout-fed flies, but we cannot confirm whether SFN derives from the radish sprout extract, whether it is formed in the organism or whether SFN is formed due to a spontaneous conversion between SFE and SFN. Support for a metabolic origin of SFN can be obtained by finding an additional SFN conjugate-SFN-cysteine (SFN-CYS) - which was also detectable in our flies ( $0.7 \mathrm{nmol} / \mathrm{g}$ F.W.). This finding suggests that GLS and ITC were metabolized in the flies and that the initial reaction between ITC and GSH may be performed as a first step in SFN-CYS conjugation [11]. It has been shown that SFN treatment elevated cellular GSH levels $[15,16]$ which prevents the accumulation of free radicals inside the cells and thereby reduces oxidative stress, which is generally associated with the development and progression of diabetes and its complications [17]. Interestingly, the distribution of GLS and ITC present in radish sprouts is partly reflected in ITC levels of our flies. The presence of the SFN-CYS metabolite in radish sprouts fed flies suggests that the metabolization of brassica-derived bioactive compounds in Drosophila melanogaster is similar to mammalian species.
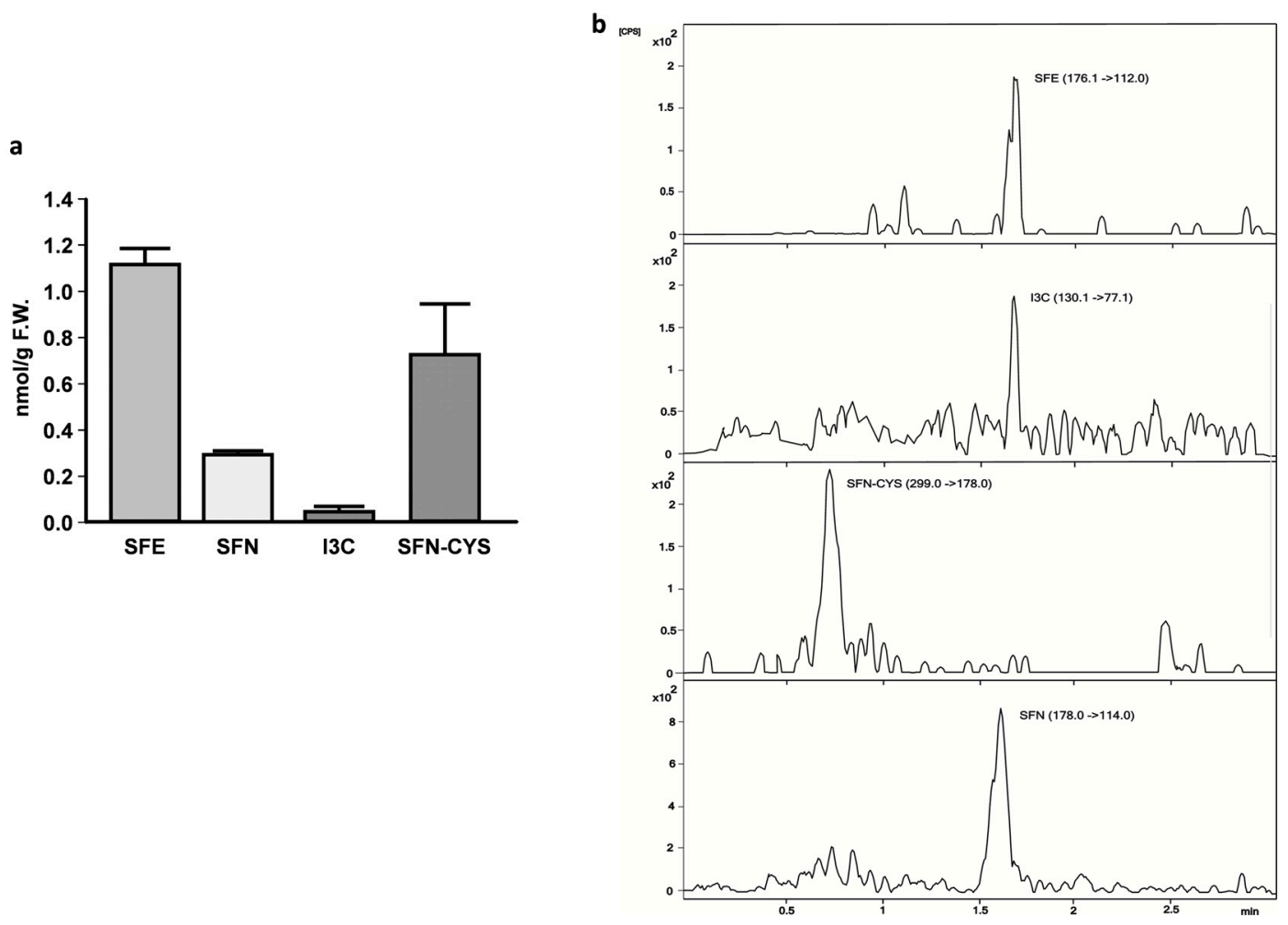

Figure 3. (a) Metabolites present in Drosophila melanogaster following the consumption of radish sprouts for 10 days; (b) Representative chromatogram of metabolites found in Drosophila melanogaster following the consumption of radish sprouts for 10 days. F.W. $=$ fresh weight, SFE $=$ sulforaphene, $\mathrm{SFN}=$ sulforaphane, $\mathrm{I} 3 \mathrm{C}=$ indole-3-carbinole, $\mathrm{SFN}-\mathrm{CYS}=$ sulforaphane-cysteine; $n=3+\mathrm{SD}$.

\subsection{Inhibition of $\alpha$-Amylase and $\alpha$-Glucosidase in Vitro by Radish Sprouts}

An aqueous extract of lyophilized radish sprouts had an inhibitory effect on $\alpha$-amylase and $\alpha$-glucosidase activity in vitro (Table 2 ). The calculated concentration of the extract required to achieve 
half of the maximal inhibitory concentration $\left(\mathrm{IC}_{50}\right)$ was higher in the $\alpha$-glucosidase inhibition assay $(60.7 \pm 1.2 \mathrm{mg} / \mathrm{mL})$ than in the $\alpha$-amylase inhibition assay $(33.8 \pm 4.0 \mathrm{mg} / \mathrm{mL})$. The concentration of $10.6 \mathrm{mg} / \mathrm{mL}$ radish sprouts which we have used in our Drosophila melanogaster experiments resulted in a $23 \%$ inhibition of the $\alpha$-amylase activity in vitro, while the in vitro $\alpha$-glucosidase activity was not affected (data not shown).

Table 2. In vitro $\alpha$-glucosidase and $\alpha$-amylase inhibitory activity of an aqueous extract of radish sprouts.

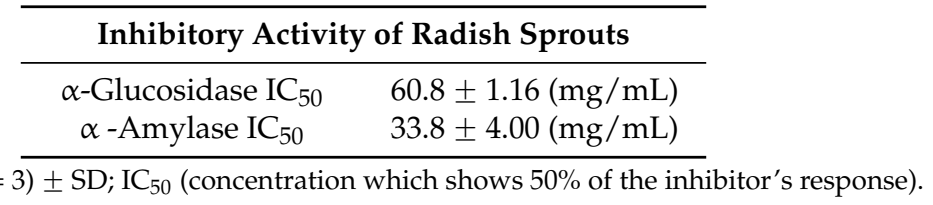

Inhibition of the enzyme $\alpha$-amylase in the intestines delays the degradation of starch and oligosaccharides to monosaccharides before they can be absorbed. The enzyme $\alpha$-glucosidase catalyzes the final step in the digestion and breakdown of carbohydrates; thus, its inhibition can be effective for the regulation of Type II diabetes through the control of glucose absorption [18]. The inhibition of $\alpha$-glucosidase may retard the digestion and absorption of carbohydrates. In addition, it may suppress post-prandial hyperglycemia, decrease calorie uptake, and result in lower levels of glucose in Drosophila melanogaster. Thus, radish sprouts may improve glucose homeostasis and provide a dietary strategy to control hyperglycemia in diabetic and obese patients. However, additional evaluation of the in vivo potential of anti-diabetic activity of radish sprouts bioactives is necessary to verify these beneficial effects.

\subsection{Energy Metabolism in Drosophila melanogaster}

The glucose levels in our radish sprout-treated flies were significantly lower than those in control flies (Figure 4a). This finding is consistent with results obtained by Okulicz and co-workers [19], who observed that I3C, a breakdown product also present in radish sprouts, affects glucose uptake in adipocytes under basal as well as under insulin-stimulated conditions.

a

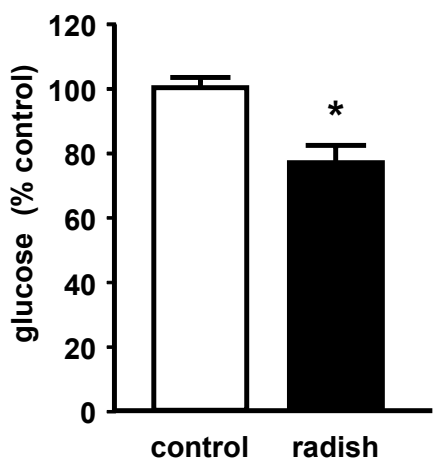

b

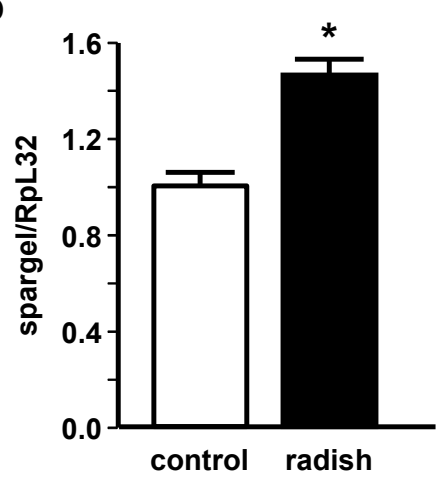

Figure 4. Effect of 10-day radish sprout supplementation on male Drosophila melanogaster. (a) relative glucose levels ( $n=9+$ SEM; extraction from $9 \times 5$ flies); (b) relative mRNA levels of spargel related to the housekeeping gene $R p L 32$ ( $n=3+$ SEM; extraction from $3 \times 5$ flies). ${ }^{*}$ indicates significant differences between control and radish sprout-fed flies $(p<0.05$, Student's $t$-test).

Because we have detected inhibition of $\alpha$-amylase in vitro by radish sprouts and decreased glucose levels in our flies, we suggest that intestinal glucose absorption decreased as a consequence of radish sprout treatment. Glucose has been described to be a pro-aging factor and to interact with several age-associated processes in the organism [20,21]. High glucose availability has been shown to shorten life span whereas a glucose restriction increased life span in the model organism 
Caenorhabditis elegans [22]. Interestingly, PGC-1 $\alpha$ has been suggested to be involved in the regulation of glucose homeostasis in mammals [23,24]. Along with decreased glucose levels, we also showed that there was an upregulation of the PGC- $1 \alpha$ homologous gene $s r l$ in Drosophila (Figure 4b). PGC- $1 \alpha / s r l$ plays an important role in the stimulation of mitochondrial biogenesis, in the reduction of ROS levels in enterocytes and stem cells, in the induction of several ROS-detoxifying enzymes and in the maintenance of optimal intestinal homeostasis [25]. Furthermore, an overexpression of PGC-1 $\alpha / \mathrm{srl}$ in the intestine of Drosophila melanogaster has been reported to be associated with life span extension [25].

Thus, we could not detect an improved resistance of our radish sprout-treated flies against both hydrogen peroxide and paraquat-induced stress (data not shown), which may be attributed to the relatively short intervention period of 10 days. However, there appears to be a connection between insulin resistance and mitochondrial dysfunction because patients suffering from type II diabetes have been reported to exhibit lower levels of mitochondria-related OXPHOS genes and PGC- $1 \alpha$ in their skeletal muscles [26,27]. In addition, insulin has been shown to induce PGC- $1 \alpha$ expression in skeletal muscle [28]. Therefore, insulin resistance may lead to a decrease in PGC-1 $\alpha$ expression and mitochondrial dysfunction, which, in turn, increases insulin resistance further [26]. An increase in PGC- $1 \alpha$ expression may provide a means to disrupt this vicious circle so that glucose homeostasis in diabetic and obese patients can be improved. Furthermore, Fernandes and co-workers have demonstrated that there is an approximately $40 \%$ increase in cellular PGC- $1 \alpha$ levels as a result of SFN administration in cultured rat cardiac myoblasts [29]. Thus, we suggest that radish sprout-derived bioactives may affect glucose homeostasis—at least partially—through the modulation of PGC-1 $\alpha$-expression.

\section{Materials and Methods}

\subsection{Radish Sprout Production}

Red radish sprouts (Raphanus sativus cv. Rambo) were germinated for 8 days, according to the protocol of Baenas et al. [7]. Briefly, sprouts were collected, flash frozen in liquid nitrogen, and stored at $-80^{\circ} \mathrm{C}$ prior to analyses. Samples were then lyophilized and ground into a fine powder before being extracted for analyses and used as fly food supplement.

\subsection{Analyses of GLS and ITC in Radish Sprouts and Drosophila Melanogaster by HPLC-DAD-ESI-MSn and UHPLC-QqQ-MS/MS}

GLS in radish sprouts were extracted and quantified by HPLC-DAD-ESI-MSn, according to the protocol of Baenas [7]. Briefly, GLS were first identified following their MS2 [M-H]-fragmentations and were then quantified following their UV spectra and order of elution as previously described for the acquisition conditions. Sinigrin and glucobrassicin were used as external standards for aliphatic and indole GLS, respectively. ITC in radish sprouts were extracted according to the protocol of Cramer and Jeffery [30] and quantified by UHPLC-QqQ-MS/MS, according to the protocol of Dominguez-Perles et al. [31]. Also, this method was used to analyze metabolites in Drosophila melanogaster. First, $200 \mathrm{mg}$ of flies were extracted with $5 \mathrm{~mL} \mathrm{MeOH}: \mathrm{H}_{2} \mathrm{O}$ (70:30), mashed with a mortar until a homogenous liquid was obtained, filtered by $0.22 \mu \mathrm{m}$ PVDF and analyzed with UHPLC-QqQ-MS/MS. The standards SFE, SFN, SFN-CYS and I3C were identified and quantified using MRM transitions and positive or negative ESI mode for quantification and confirmation of the target analytes. Analyses of GLS and ITC of radish sprouts were conducted in triplicate.

\subsection{In Vitro $\alpha$-Amylase and $\alpha$-Glucosidase Assay of Radish Sprouts}

The $\alpha$-amylase and $\alpha$-glucosidase inhibition assay was performed using a protocol modified from Phan et al. [32]. Samples of lyophilized radish sprouts $(n=3)$ were extracted with distilled water. The extracts were tested for $\alpha$-glucosidase and $\alpha$-amylase inhibition as previously described [33]. 
Acarbose was used as a positive control and was equally dissolved in distilled water. $\mathrm{IC}_{50}$ values were calculated using the program GraphPad prism (La Jolla, CA, USA).

\subsection{Drosophila melanogaster Stocks and Treatment}

In the present study, $\mathrm{W}^{1118}$ Drosophila melanogaster was used for the experiments. Flies were maintained under conventional conditions on sugar yeast medium (SY) containing 10\% sucrose (Carl Roth, Karlsruhe, Germany), 10\% inactive dry yeast, 2\% agar, 0.3\% nipagin (all Dominique Dutscher SAS, Brumath, France), and 0.3\% propionic acid (Carl Roth) in a climate chamber (HPP 1018, Memmert, Schwabach, Germany) under the following constant conditions: a temperature of $25^{\circ} \mathrm{C}$, relative humidity of $60 \%$ and 12 -h day/night cycle. For all of the experiments, age-matched flies from synchronized eggs were used [34]. The SY medium was supplemented with radish sprouts at a concentration of $10.6 \mathrm{~g} / \mathrm{L}$, containing $50 \mu \mathrm{mol} / \mathrm{L}$ of the ITC SFE.

\subsection{Gustatory Assay}

This method was performed to exclude differences in food intake between control flies and radish sprouts treated flies. The gustatory assay was performed as described earlier [34]. In brief, 15 flies were kept on SY medium or SY+radish sprouts. Both were supplemented with $0.2 \% w / v$ sulforhodamine B sodium salt (Sigma-Aldrich, Steinheim, Germany) and kept under standard conditions for $500 \mathrm{~min}$. Next, the flies were homogenized in PBS (Life Technologies by Thermo Fisher Scientific, Darmstadt, Germany) plus 1\% Triton ${ }^{\mathrm{TM}}$ X-100 (Sigma-Aldrich) using a Qiagen TissueLyser II (Hilden, Germany). The flies were then centrifuged, and the absorbance was measured in an Infinite 200 spectrophotometer (Tecan, Crailsheim, Germany) at 535/25 nm excitation and 590/20 nm emission wavelength.

\subsection{Negative Geotaxis Assay: Climbing Activity}

Climbing ability was considered to be an indicator of overall fitness of the flies, which were maintained under control conditions (SY) and under SY+radish sprouts for 10 days. On day 10, flies were transferred into empty vials to perform the rapid iterative negative geotaxis (RING)-assay as previously described [33].

\subsection{Glucose Analysis}

Flies were maintained either on SY $(n=20)$ or SY+radish sprouts under standard conditions for 10 days. Five flies per sample were homogenized in PBS $/ 1 \%$ Triton ${ }^{\mathrm{TM}} \mathrm{X}-100$ using a Qiagen TissueLyser II. The supernatant was removed and analyzed for glucose content with Fluitest ${ }^{\circledR}$ GLU (Analyticon Biotechnologies, Lichtenfels, Germany) according to the manufacturer's protocol. Sample concentrations were calculated via the standard curve and related to the corresponding fly weights. The weighing of flies was performed using previously described methods [35].

\subsection{Real-Time PCR}

Total RNA was isolated from 5 flies per sample using peqGOLD TriFast ${ }^{\mathrm{TM}}$ (Peqlab, Erlangen, Germany) according to the manufacturer's protocol. RNA concentration was determined using a NanoDrop ${ }^{\circledR}$ spectrophotometer (Thermo Scientific, Schwerte, Germany). Primer sequences for Drosophila melanogaster spargel (srl) are described elsewhere [36]. Primers for the housekeeping gene Drosophila melanogaster Ribosomal protein L32 (RpL32) (forward 5'-GGCAAGCTTCAAGATGACCA-3'; reverse $5^{\prime}$-GTTCGATCCGTAACCGATGT-3') were designed by Primer3 software (Whitehead Institute for Biomedical Research, Cambridge, MA, USA). All primers were purchased from MWG Biotech (Ebersberg, Germany). Real-time PCR was performed using the SensiFastTM SYBR ${ }^{\circledR}$ No-ROX One-Step kit (Bioline, Luckenwalde, Germany) on a Rotor-Gene 6000 cycler (Corbett Life Science, Sydney, Australia). The expression of $s r l$ was related to the expression of the housekeeping gene $R p L 32$. 


\subsection{Statistics}

The results are presented as the mean \pm SEM unless otherwise indicated. All data were analyzed using SPSS software (Statistical Package for the Social Sciences, IBM, Armonk, NY, USA). The significance of the differences between the control and radish sprout-treated flies was evaluated using a Student's $t$-test. All data were tested for normality of distribution (Shapiro-Wilk) and the homogenicity of variances (Levene). Significance was accepted at $p$-values $<0.05$.

\section{Conclusions}

In the present study, we showed, for the first time, that plant bioactives present in radish sprouts are absorbed and hydrolyzed by Drosophila melanogaster either due to the presence of plant-derived or Drosophila-derived microbial myrosinase in the gut. The presence of SFN-CYS in fly homogenates suggests that ITC are metabolized by fruit flies. The intake of radish sprouts decreased the glucose content in our flies and increased srl expression levels, thereby modulating energy metabolism. Understanding the factors that determine the absorption and effects of ITC in in vivo models is critical for identifying effective dosages that can be used in nutritional studies. As we have only analyzed flies on a radish sprout-supplemented diet for 10 days, analyses of flies receiving radish sprout-supplemented food for a longer period are sorely needed to assess the robustness of our results. To confirm the involvement of $s r l$ in the potential beneficial metabolic effects of radish sprouts, life span studies are important. Additionally, studies in mammalian species are needed to confirm our results that were obtained in the model organism Drosophila melanogaster.

Author Contributions: Nieves Baenas, Stefanie Piegholdt, Diego A. Moreno, Cristina García-Viguera, Gerald Rimbach and Anika E. Wagner conceived and designed the experiments; Nieves Baenas, Stefanie Piegholdt and Anke Schloesser performed the experiments; Nieves Baenas, Stefanie Piegholdt and Anke Schloesser analyzed the data; Nieves Baenas, Stefanie Piegholdt, Gerald Rimbach and Anika E. Wagner wrote the paper.

Conflicts of Interest: The authors declare no conflict of interest.

\section{Abbreviations}

$\begin{array}{ll}\text { GLS } & \text { glucosinolates } \\ \text { ITC } & \text { isothiocyanates } \\ \text { PGC1 } \alpha & \text { PPAR } \gamma \text { co-activator } 1 \alpha \\ \text { PPAR } \gamma & \text { peroxisome proliferator activated receptor } \gamma \\ \text { GSH } & \text { glutathione } \\ \text { GST } & \text { glutathione-S-transferase } \\ \text { NAC } & \text { N-acetyl-cysteine } \\ \text { cys } & \text { cysteine } \\ \text { cys-gly } & \text { cysteinylglycine } \\ \text { SFE } & \text { sulforaphene } \\ \text { SFN } & \text { sulforaphane } \\ \text { RPS } & \text { raphasatin } \\ \text { SFN-CYS } & \text { sulforaphane-cysteine } \\ \text { R } p \text { 32 } & \text { Drosophila melanogaster ribosomal protein L32 } \\ \text { Srl } & \text { spargel }\end{array}$

\section{References}

1. Tzioumis, E.; Adair, L.S. Childhood dual burden of under- and overnutrition in low- and middle-income countries: A critical review. Food Nutr. Bull. 2014, 35, 230-243. [CrossRef] [PubMed]

2. Bahadoran, Z.; Mirmiran, P.; Azizi, F. Potential efficacy of broccoli sprouts as a unique supplement for management of type 2 diabetes and its complications. J. Med. Food 2013, 16, 375-382. [CrossRef] [PubMed] 
3. Dinkova-Kostova, A.T.; Kostov, R.V. Glucosinolates and isothiocyanates in health and disease. Trends Mol. Med. 2012, 18, 337-347. [CrossRef] [PubMed]

4. Zia-Ul-Haq, M.; Cavar, S.; Qayum, M.; Imran, I.; de Feo, V. Compositional studies: Antioxidant and antidiabetic activities of Capparis decidua (Forsk.) Edgew. Int. J. Mol. Sci. 2011, 12, 8846-8861. [CrossRef] [PubMed]

5. Poornima, J.; Mirunalini, S. Regulation of carbohydrate metabolism by indole-3-carbinol and its metabolite 3,3'-diindolylmethane in high-fat diet-induced C57BL/6J mice. Mol. Cell. Biochem. 2014, 385, 7-15. [CrossRef] [PubMed]

6. Bahadoran, Z.; Mirmiran, P.; Hosseinpanah, F.; Rajab, A.; Asghari, G.; Azizi, F. Broccoli sprouts powder could improve serum triglyceride and oxidized LDL/LDL-cholesterol ratio in type 2 diabetic patients: A randomized double-blind placebo-controlled clinical trial. Diabetes Res. Clin. Pract. 2012, 96, 348-354. [CrossRef] [PubMed]

7. Baenas, N.; Garcia-Viguera, C.; Moreno, D.A. Biotic elicitors effectively increase the glucosinolates content in Brassicaceae sprouts. J. Agric. Food Chem. 2014, 62, 1881-1889. [CrossRef] [PubMed]

8. Papi, A.; Orlandi, M.; Bartolini, G.; Barillari, J.; Iori, R.; Paolini, M.; Ferroni, F.; Grazia Fumo, M.; Pedulli, G.F.; Valgimigli, L. Cytotoxic and antioxidant activity of 4-methylthio-3-butenyl isothiocyanate from Raphanus sativus L. (kaiware daikon) sprouts. J. Agric. Food Chem. 2008, 56, 875-883. [CrossRef] [PubMed]

9. Kim, J.W.; Kim, M.B.; Lim, S.B. Formation and stabilization of raphasatin and sulforaphene from radish roots by endogenous enzymolysis. Prev. Nutr. Food Sci. 2015, 20, 119-125. [CrossRef] [PubMed]

10. Chang, H.P.; Wang, M.L.; Chan, M.H.; Chiu, Y.S.; Chen, Y.H. Antiobesity activities of indole-3-carbinol in high-fat-diet-induced obese mice. Nutrition 2011, 27, 463-470. [CrossRef] [PubMed]

11. Angelino, D.; Jeffery, E. Glucosinolate hydrolysis and bioavailability of resulting isothiocyanates: Focus on glucoraphanin. J. Funct. Foods 2014, 7, 67-76. [CrossRef]

12. Cartea, E.; Velasco, P. Glucosinolates in brassica foods: Bioavailability in food and significance for human health. Phytochem. Rev. 2008, 7, 213-229. [CrossRef]

13. Wagner, A.E.; Terschluesen, A.M.; Rimbach, G. Health promoting effects of brassica-derived phytochemicals: From chemopreventive and anti-inflammatory activities to epigenetic regulation. Oxidative Med. Cell. Longev. 2013, 2013, 964539. [CrossRef] [PubMed]

14. Scholl, C.; Eshelman, B.D.; Barnes, D.M.; Hanlon, P.R. Raphasatin is a more potent inducer of the detoxification enzymes than its degradation products. J. Food Sci. 2011, 76, C504-C511. [CrossRef] [PubMed]

15. Dias, I.H.; Chapple, I.L.; Milward, M.; Grant, M.M.; Hill, E.; Brown, J.; Griffiths, H.R. Sulforaphane restores cellular glutathione levels and reduces chronic periodontitis neutrophil hyperactivity in vitro. PLoS ONE 2013, 8, e66407.

16. Steele, M.L.; Fuller, S.; Patel, M.; Kersaitis, C.; Ooi, L.; Munch, G. Effect of Nrf2 activators on release of glutathione, cysteinylglycine and homocysteine by human U373 astroglial cells. Redox Biol. 2013, 1, 441-445. [CrossRef] [PubMed]

17. Tiwari, B.K.; Pandey, K.B.; Abidi, A.B.; Rizvi, S.I. Markers of oxidative stress during diabetes mellitus. J. Biomark. 2013, 2013, 378790. [CrossRef] [PubMed]

18. Rubilar, M.; Jara, C.; Poo, Y.; Acevedo, F.; Gutierrez, C.; Sineiro, J.; Shene, C. Extracts of maqui (Aristotelia chilensis) and murta (Ugni molinae Turcz.): Sources of antioxidant compounds and $\alpha$-glucosidase $/ \alpha$-amylase inhibitors. J. Agric. Food Chem. 2011, 59, 1630-1637. [CrossRef] [PubMed]

19. Okulicz, M.; Hertig, I.; Chichlowska, J. Effects of indole-3-carbinol on metabolic parameters and on lipogenesis and lipolysis in adipocytes. Czech J. Anim. Sci. 2009, 54, 182-189.

20. Kassi, E.; Papavassiliou, A.G. Could glucose be a proaging factor? J. Cell. Mol. Med. 2008, 12, 1194-1198. [CrossRef] [PubMed]

21. Leontieva, O.V.; Demidenko, Z.N.; Blagosklonny, M.V. Rapamycin reverses insulin resistance (IR) in high-glucose medium without causing IR in normoglycemic medium. Cell Death Dis. 2014, 5, e1214. [CrossRef] [PubMed]

22. Schulz, T.J.; Zarse, K.; Voigt, A.; Urban, N.; Birringer, M.; Ristow, M. Glucose restriction extends caenorhabditis elegans life span by inducing mitochondrial respiration and increasing oxidative stress. Cell Metab. 2007, 6, 280-293. [CrossRef] [PubMed]

23. Herzig, S.; Long, F.; Jhala, U.S.; Hedrick, S.; Quinn, R.; Bauer, A.; Rudolph, D.; Schutz, G.; Yoon, C.; Puigserver, P.; et al. Creb regulates hepatic gluconeogenesis through the coactivator PGC-1. Nature 2001, 413, 179-183. [CrossRef] [PubMed] 
24. Yoon, J.C.; Puigserver, P.; Chen, G.; Donovan, J.; Wu, Z.; Rhee, J.; Adelmant, G.; Stafford, J.; Kahn, C.R.; Granner, D.K.; et al. Control of hepatic gluconeogenesis through the transcriptional coactivator PGC-1. Nature 2001, 413, 131-138. [CrossRef] [PubMed]

25. Rera, M.; Bahadorani, S.; Cho, J.; Koehler, C.L.; Ulgherait, M.; Hur, J.H.; Ansari, W.S.; Lo, T., Jr.; Jones, D.L.; Walker, D.W. Modulation of longevity and tissue homeostasis by the Drosophila PGC-1 homolog. Cell Metab. 2011, 14, 623-634. [CrossRef] [PubMed]

26. Lin, J.; Handschin, C.; Spiegelman, B.M. Metabolic control through the PGC-1 family of transcription coactivators. Cell Metab. 2005, 1, 361-370. [CrossRef] [PubMed]

27. Patti, M.E.; Butte, A.J.; Crunkhorn, S.; Cusi, K.; Berria, R.; Kashyap, S.; Miyazaki, Y.; Kohane, I.; Costello, M.; Saccone, R.; et al. Coordinated reduction of genes of oxidative metabolism in humans with insulin resistance and diabetes: Potential role of PGC1 and Nrf1. Proc. Natl. Acad. Sci. USA 2003, 100, 8466-8471. [CrossRef] [PubMed]

28. Ling, C.; Poulsen, P.; Carlsson, E.; Ridderstrale, M.; Almgren, P.; Wojtaszewski, J.; Beck-Nielsen, H.; Groop, L.; Vaag, A. Multiple environmental and genetic factors influence skeletal muscle PGC-1 $\alpha$ and $P G C-1 \beta$ gene expression in twins. J. Clin. Investig. 2004, 114, 1518-1526. [CrossRef] [PubMed]

29. Fernandes, R.O.; Bonetto, J.H.; Baregzay, B.; de Castro, A.L.; Puukila, S.; Forsyth, H.; Schenkel, P.C.; Llesuy, S.F.; Brum, I.S.; Araujo, A.S.; et al. Modulation of apoptosis by sulforaphane is associated with PGC-1 $\alpha$ stimulation and decreased oxidative stress in cardiac myoblasts. Mol. Cell. Biochem. 2015, 401, 61-70. [CrossRef] [PubMed]

30. Cramer, J.M.; Jeffery, E.H. Sulforaphane absorption and excretion following ingestion of a semi-purified broccoli powder rich in glucoraphanin and broccoli sprouts in healthy men. Nutr. Cancer 2011, 63, $196-201$. [CrossRef] [PubMed]

31. Dominguez-Perles, R.; Medina, S.; Moreno, D.A.; Garcia-Viguera, C.; Ferreres, F.; Gil-Izquierdo, A. A new ultra-rapid UHPLC/MS/MS method for assessing glucoraphanin and sulforaphane bioavailability in human urine. Food Chem. 2014, 143, 132-138. [CrossRef] [PubMed]

32. Phan, M.A.T.; Wang, J.; Tang, J.Y.; Lee, Y.Z.; Ng, K. Evaluation of $\alpha$-glucosidase inhibition potential of some flavonoids from epimedium brevicornum. LWT Food Sci. Technol. 2013, 53, 492-498. [CrossRef]

33. Wagner, A.E.; Piegholdt, S.; Rabe, D.; Baenas, N.; Schloesser, A.; Eggersdorfer, M.; Stocker, A.; Rimbach, G. Epigallocatechin gallate affects glucose metabolism and increases fitness and lifespan in Drosophila melanogaster. Oncotarget 2015, 6, 30568-30578. [PubMed]

34. Linford, N.J.; Bilgir, C.; Ro, J.; Pletcher, S.D. Measurement of lifespan in Drosophila melanogaster. J. Vis. Exp. 2013, 7, 50068.

35. Piegholdt, S.; Rimbach, G.; Wagner, A.E. The phytoestrogen prunetin affects body composition and improves fitness and lifespan in male Drosophila melanogaster. FASEB J. 2016, 30, 948-958. [CrossRef] [PubMed]

36. Tinkerhess, M.J.; Healy, L.; Morgan, M.; Sujkowski, A.; Matthys, E.; Zheng, L.; Wessells, R.J. The Drosophila PGC-1 $\alpha$ homolog spargel modulates the physiological effects of endurance exercise. PLoS ONE 2012, 7, e31633. [CrossRef] [PubMed]

(C) 2016 by the authors; licensee MDPI, Basel, Switzerland. This article is an open access article distributed under the terms and conditions of the Creative Commons by Attribution (CC-BY) license (http://creativecommons.org/licenses/by/4.0/). 